\title{
Evaluation of living conditions of free-ranging animals by automated chronobiological analysis of behavior
}

\author{
A. BERGER, K.-M. SCHEIBE, S. MICHAELIS, and W. J. STREICH \\ Institute for Zoo Biology and Wildlife Research, Berlin, Germany
}

\begin{abstract}
A biorhythmical method has been developed to assess behavior patterns and to evaluate the living conditions of animals that can be applied also to humans. All kinds of continuous and equidistant longterm recordings of behavior are suitable for this method. Time functions from an automatic telemetry system (ETHOSYS II) were analyzed macroscopically (comparison of daily levels) and microscopically (autocorrelation function and power spectral analysis). Degrees of functional coupling (DFCs) were calculated to identify and evaluate disturbances in behavior. Hierarchic frequency tuning of complex rhythmic functions of behaviors, leads primarily to period lengths that are synchronized with the 24-h period. DFCs, a measure of harmony between internal rhythms and the external 24-h period, were found to be high in well-adapted, healthy, and undisturbed individuals but were lowered during periods of adaptation, sickness, or social interaction. Specific stress conditions could be identified and evaluated in several species, under various conditions, using these biorhythmic analyses.
\end{abstract}

Change in living conditions usually entails behavioral adaptation. Such adaptation can be monitored by analyzing both intensity and rhythmicity of behaviors. General locomotor activity, being the final link in a long chain of internal processes, is reflected by both internal motivation and external stimuli and is characterized by continuous alternation between motion and rest (Szymanski, 1920). The circadian rhythm of activity can be interpreted as a programmed control, tuning the organism as a whole to periodic changes of environmental conditions. Close and well-defined meaningful coordination between time structures of different physiological and behavioral functions seems to be characteristic of the healthy organism. Since the circadian rhythm is the most influential factor, all the other rhythms are more or less related to it. Fixed phase relations have been described in humans-for example, between body temperature, activity, and excretion of minerals (Aschoff, Gerecke, \& Wever, 1967). To describe such a correlation between different physiological and behavioral parameters, Aschoff (1969) used the term internal synchronization.

External stressors act as disturbances on this regulatory system. A changing internal state will influence the present value of the system. Both may change the intensity of behaviors and also the time structure of behavior. Although variations in intensity of behavior are easily detectable by short-time observation and sample collection, analysis of rhythm is not valid unless it is based on

Correspondence concerning this article should be addressed to A. Berger, Institut für Zoo- und Wildtierforschung, Alfred-Kowalke Str. 17, D-10315 Berlin, Germany (e-mail: berger@izw-berlin.de). long-term uninterrupted data acquisition. For example, a recording period of $312 \mathrm{~h}$ would be required for differentiation between two rhythms of 24 or $26 \mathrm{~h}$ in period length (Mercer, 1965). Such demands can hardly be met by direct telemetry, since temporary disruption of data transmission cannot be totally ruled out. Direct telemetry for behavior analysis is difficult to perform over long distances or if high numbers of individuals are involved. It is difficult to affix several sensors to different parts of one animal body. Connections between sensors and transmitter are critical, and radio transmission of data may be interrupted by physical obstacles or long distance.

Direct measurement of stress (e.g., by endocrinological parameters in blood samples) is not practical in freeranging animals. Side-effects of sampling may be stronger than the effect of the original stressor. However, weak stressors, quite often of long duration, are characteristic of the environmental conditions of these animals. Wild animals, like domestic species, may suffer from maninduced influences or diseases. Wild animals do not display their suffering but conceal it as far as possible, in order not to attract predators or to lose protection by their social group. Nevertheless, long-term effects may become manifest in the frequency and time structure of behavior. Since simple behavioral parameters, such as activity, can be conveniently recorded by telemetry, it should be possible to investigate such stressors by following biological rhythms.

We developed a procedure for quantification of the harmonic frequency structure of behavioral rhythms on various species under different conditions, based on telemetric long-term measurements of activity and feeding. It is the purpose of this report to describe the basic idea 
and the procedure, to give some examples of application, and to discuss the potential benefit of the general application on man as well.

\section{Material and Methods}

Data acquisition on free-ranging animals. The ETHOSYS II system is made up of collars (ETHOREC), a transceiver (ETHOLINK), and software for laptop or PC (ETHODAT; Scheibe \& Schleusner, 1993; Figure 1).

The ETHOREC collar has attached to it sensors, data processing facilities for interpretation of signal patterns, a microcontroller with memory (RAM), a radio receiver, and a transmitter for communication. Every collar has two built-in sensors, one for acceleration and the other for position tracking of the animal's head (up or down). A piezoelectric element (Type PKS 41/MURATA), 2,000 mg in mechanical load, is used as an acceleration sensor. Species-specific and behavior-specific angular positions of the collar may be identified by means of either a position detector (Type CW 1300-1/Pewatron) or a Type NSW 1/GEMAC position detector with a reed switch. The raw data emitted by sensors are processed in a logic network. The output comes in four one-bit channels, each of them representing a different type of behavior (Figure 2).

Channel 1 is used to measure movements as an indicator of general locomotor activity. Any body movement is rated as an activity, whether the animal is in a standing or a recumbent position.

If at least one signal from the acceleration sensor is picked up during an interval of $1 \mathrm{sec}$, this second is defined and counted as an interval of activity. Linked to
Channel 2 is the logic connection between general activity and the head-down signal from the position sensor. If these definitions are true, $1 \mathrm{sec}$ is counted as activity with head down.

The microcontroller can be programmed to identify impulse intervals between 125 and 2,000 msec for interpretation of signals emitted from the acceleration sensor. If these signal patterns are identified, the corresponding intervals are also counted and can be logically connected to the position information. The user has to define rhythm and variability of the specific behavior which is to be identified. For example, a specific pattern of movements with head down can be identified as feeding. The logic network must be programmed, and frequency filters need to be set to species and research of interest. Versions have so far been designed for sheep (Ovis aries), mouflon (Ovis ammon musimon), cattle (Bos taurus), alpacas (Lama pacos), horses (Equus przewalskii), roe deer (Capreolus capreolus), fallow deer (Dama dama), and red deer (Cervus elaphus).

Basically, the combination of motion, motion frequency, and position can be used to identify four different behavior patterns of animals and humans that can be characterized by these criteria. The duration of these behaviors can be measured during fixed intervals.

On completion of a programmed interval, which may be up to $60 \mathrm{~min}$, the counted total will be saved as the dependent variable for this interval, and counting will start all over again. The variable measured for each of the time intervals may vary between $0 \%$ and $100 \%$ or the number of seconds of the interval. This sample method corresponds to the focal animal sampling method de-

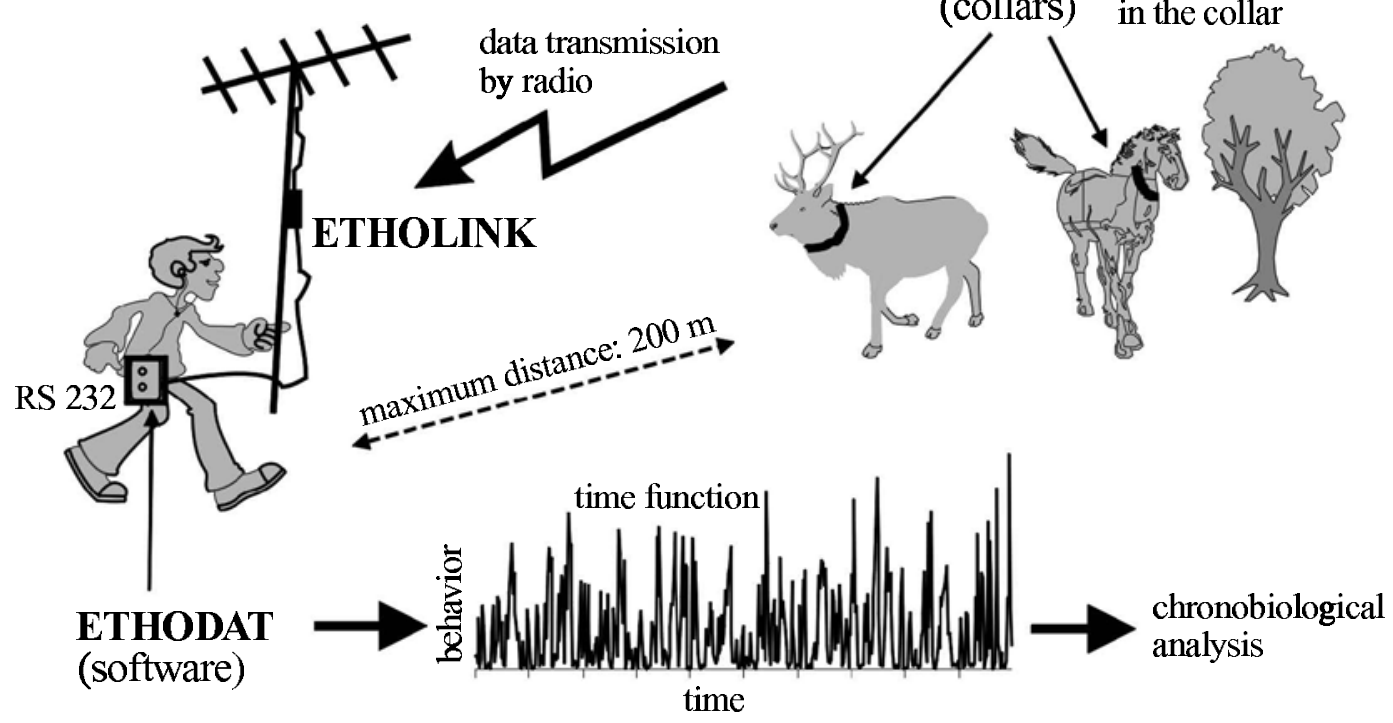

Figure 1. The storage telemetry system ETHOSYS. The ETHOREC registration device is designed as a collar. ETHOLINK is a high-frequency transceiver. ETHODAT software can be used on a laptop or a PC. ETHOLINK can communicate with several ETHORECs. 


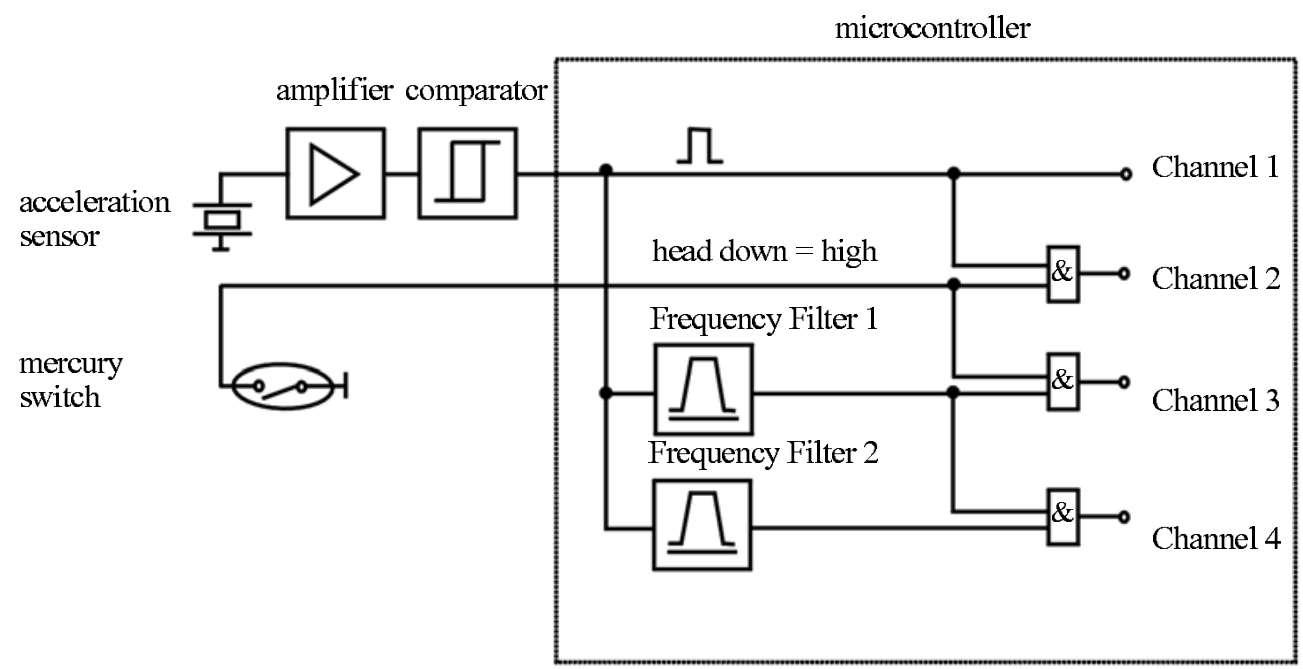

Figure 2. Functional block diagram of the sensor unit of ETHOREC. Signals from an acceleration sensor are taken up by Channel 1, with Channel 2 counting accelerations depending on the state of the position sensor. The other two channels contain information depending on accelerations that pass Frequency Filters 1 and 2, as well as on the state of the position sensor.

scribed by Altmann (1974) and is particularly suitable for analysis of sequential constraints, percentages of time, rates, and durations.

Summarized results are stored in the flash RAM. Memory capacity is sufficient for 4,000 data sets. With 1 -h intervals of analysis, a collar can function independently of the central station without any loss of data for 166 days. Even with 5-min intervals of analysis, its operational capability will be 2 weeks. Earlier data are overwritten, so that most recent results will be available at all times.

Power is supplied to the collar from two 3.6-V/2-Ah Li-batteries, sufficient for 1 year of recording.

The transmitter is activated as soon as a signal from ETHOLINK is identified by the radio receiver. The collar identification code then will be emitted, followed by transmission of data from the memory. Complete reception of a data set is acknowledged by a separate signal, and only then will the memory be cleared to provide space for future entries.

ETHOLINK is a high-frequency transceiver (434 MHz), controlled by a PC. The ETHODAT program is data linked through the RS 232 interface to ETHOLINK. It is used to select an ETHOREC for downloading of data and data storage in ASCII files on the PC. Listed in each of the files are the date, time of day, and length of behavior in seconds in the given interval for the four channels.

Data analysis. All kinds of continuous and equidistant long-term recordings of behavior, stored as ASCII files, are suitable for the following data analysis.

For preliminary visual inspection and macroscopic analysis, data were organized in daily data sets by means of a procedure (plot), and plots were displayed by EXCEL. They show the duration of behavior during the analysis intervals, coded in colors or gray in daily records, which are displayed one beneath the other. On the basis of this data structure, deviation in daily levels or switching from daytime activity to nighttime activity can easily be identified. For microscopical analysis, all data series (measuring interval, $1 \mathrm{sec}$; storing interval, $15 \mathrm{~min}$; data varied between 0 and 900), as recorded for each individual for activity and feeding, were checked for their relative rhythmic components. The calculations were performed by self-written programs named "time" (DOS version) and "Wifostat" (Windows version).

The measure to be defined should describe the degree of synchronization between internal rhythms and the external 24-h period. This makes sense for time periods containing not too many subsequent days. Therefore, equivalent to the procedure of moving average, all data files were subdivided into data sets of 7 consecutive days, with a shift by 1 day and overlapping 6 days between successive data sets (means: first data set goes from 1 st to 7 th day, second data set from 2 nd to 8 th day, third data set from 3rd to 9th day, and so on).

Autocorrelation functions were calculated for each of those partially overlapping data files to reduce the noise component.

From these calculated autocorrelation functions, the power spectra were drawn, consisting of the periodogram ordinates for all Fourier frequencies $\omega=2 \pi j / n, j=1, \ldots$, $q$ with $q=n / 2$ ( $n$ even) or $q=n / 2-1(n$ odd $)$, with $n$ being the number of data points in the sample; Scheibe, Berger, Langbein, Streich, \& Eichhorn, 1999). The periodogram ordinates (which are basically variance components assigned to cyclic fluctuations containing $n / j$ data points per cycle, $j=1, \ldots, q$ ) were tested for sta- 
tistical significance (test according to R. A. Fisher; Andel, 1984) and provided the significant periodic components of the original data series.

The values of the significant periods were used to calculate the degree of functional coupling (DFC; Scheibe, Berger, Langbein, Streich, \& Eichhorn, 1999) and the harmonic part (HP). DFC expresses the relationship between the total intensities of significant harmonic periods $[S I($ harm $)]$ and the total intensities of all significant periods [SI(total); see Equation 1]. Here, harmonic periods are defined as periods that are synchronized by an integral number relationship with the circadian zeitgeber (i.e., $24 \mathrm{~h}$ divided by $1,2,3$, etc. gives harmonic periods):

$$
\mathrm{DFC}[\%]=S I(\text { harm }) * 100 / S I \text { (total). }
$$

$S P$ (total) denotes the sum of all significant periodogram ordinates (i.e., the variance assigned to significant periods). $S P$ (harm) denotes the sum of those periodogram ordinates that are significant and harmonic to the circadian period.

DFCs describe that percentage of total power of cyclic behavior components synchronized with the most important external rhythm - the 24-h period. DFCs varied between $100 \%$ (i.e., only harmonic periods were significant; maximal internal synchronization of organism and between organism and environment) and $0 \%$ (i.e., only nonharmonic periods were significant; desynchronization).

The harmonic part is defined as

$$
\mathrm{HP}[\%]=100 * S I(\text { harm }) / S T \text {. }
$$

In this case, the harmonic rhythms are related to the total power of the spectrum $(S T)$. Since $S T$ includes all the components of a spectrum, the HP expresses the relation of harmonic components to the noise level in the spectrum.

The resulting DFCs and HPs were continuously mapped for each of the animals throughout the year and were statistically compared with points in time at which unusual external influences occurred.

Animals. We monitored the behavior of Przewalski horses and mouflon in the Schorfheide/Liebenthal semireserve. Twelve zoo-born mares lived in that area, without additional feeding or any other human influence. We took activity records at irregular intervals over 5 years.

Red deer were investigated in two research enclosures. One male was on an experimental pasture of $3,800 \mathrm{~m}^{2}$ in Theix (INRA Clermont-Ferrand, France). Although the nutritional demands of the animals were covered by the pasture, a small ration of concentrates was additionally offered once a day. Two female red deer were subjects of comparative research on a near-natural site of $0.4 \mathrm{~km}^{2}$ in Velcice (Slovakia), in cooperation with the Institute of Wildlife Research and Ecology (Vienna). These animals lived in a herd of 16. Hay was additionally offered ad lib but was rarely accepted.

Behavior recordings were obtained from free-ranging mouflons on an island north of Berlin. The animals were members of a population of approximately 120 individuals, inhabiting an area of $7 \mathrm{~km}^{2}$. They were accustomed to a salt lick and to a feeding place where small amounts of food were provided for attraction.

A study was conducted on behavioral rhythms in a group of 5 alpacas kept in Tierpark Berlin-Friedrichsfelde. The animals ( 1 stallion and 4 females) lived on a pasture of $3,700 \mathrm{~m}^{2}$ but were kept in stables overnight. Food was provided daily in the stable in the evening. Additional feed was offered on the pasture, especially in winter.

Efforts were made in all the studies to obtain additional information on social conditions, animal state, and external influences.

\section{Results}

An overview of the long-term organization of activity (A) and feeding (B) is given in Figure 3 by an example of mouflon measured by ETHOSYS II. This example gives a good impression of hierarchic functional order and dynamic interrelation among the different components of the biological rhythms. It consists of a changing daily level of the behaviors during the year, as a 24-h component, of components related to sunrise and sunset and of a varying of ultradian rhythms. There are several activity peaks also during the night throughout the year. Annual change in activity is obvious and differs moderately from the annual pattern of feeding. High and low levels of activity and feeding during the year are visible.

DFCs from several situations and species are compared in Table 1. DFCs were significantly lowered in periods of adaptation, changes of physiological status, or stress. Disturbances or adaptational periods reduced the external and the internal coordination. The same effect was observed, not only when an animal was injured, but also during normal changes of physiological state, as in the week of parturition. Even different holding conditions were manifested in varying DFCs. DFCs declined within behavior that was directly affected by the disturbance. So with red deer, a change of food caused minimum values of feeding DFCs but had no impact on activity DFCs. This demonstrates how disturbances can be detected within the functional behavioral circles affected by a special external disturbance.

The immediate and drastic change of DFCs will be demonstrated in two examples.

One time series was recorded from 1 Przewalski horse during its stay in the zoo, its transportation from zoo to the semireserve, and the subsequent period in the semireserve. The single DFCs of activity are depicted as an example of adaptation to seminatural conditions (Figure 4). DFCs were very high during the zoo period $(97.1 \%)$, drastically lower during the period of adaptation $(40 \%)$, and slowly recovered to mean values $(55 \%)$, which, however, were clearly even lower than the mean DFC of activity for the total herd during the same period of time (80.6\%). Varying DFCs for activity, with a mean value of $85.5 \%$, were characteristic of a Przewalski horse 

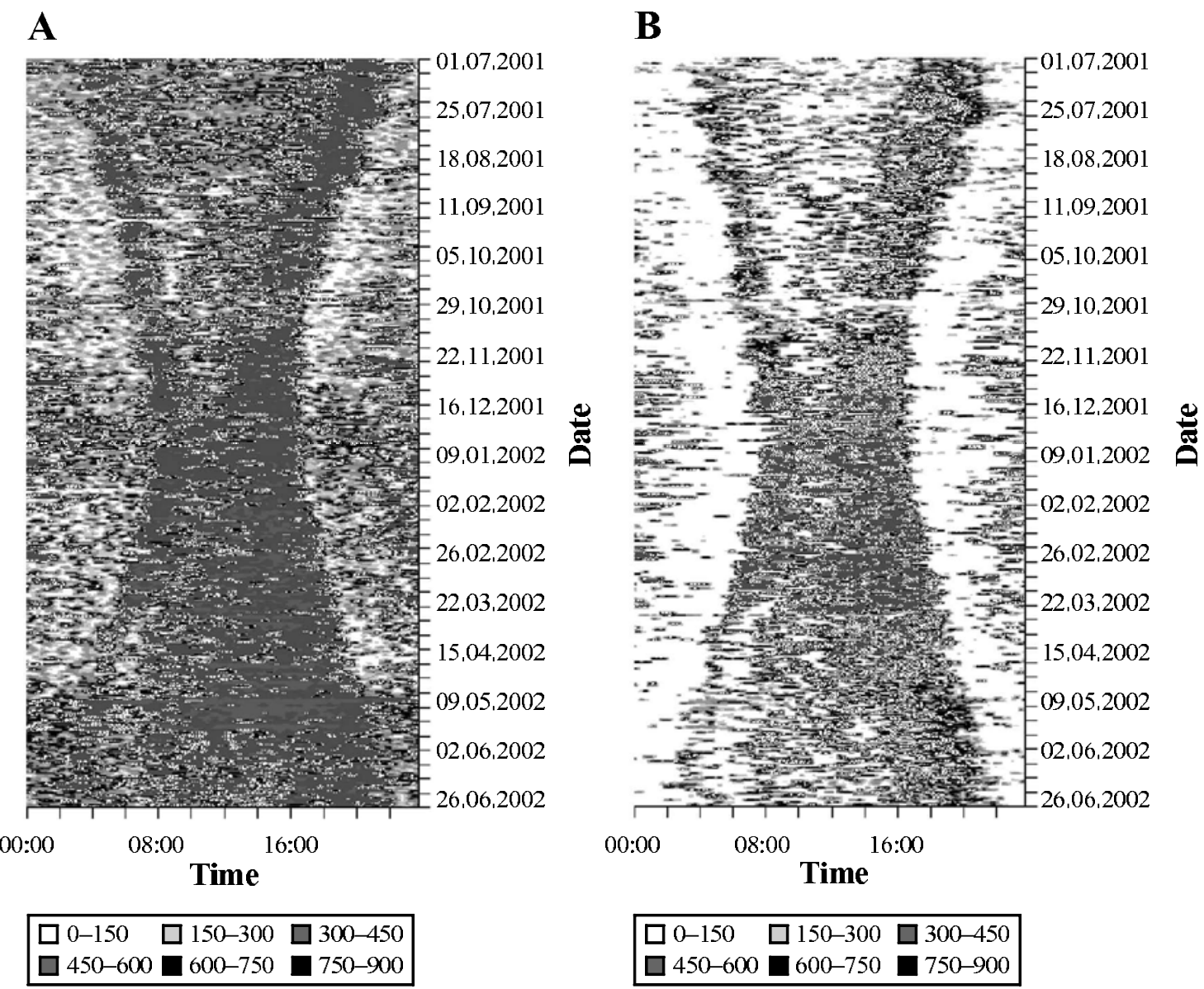

Figure 3. Annual pattern of activity (A) and feeding (B) of mouflon under naturelike conditions measured by ETHOSYS II.

for up to 2 years from introduction to the semireserve. Somewhat higher DFCs occurred after 2 years (mean value of $90.3 \%$ ), and a more stable and harmonious activity pattern was visible.

In 1 sheep with parasitic infection, about 1 month before death, structural changes could be found in activity and grazing. They consisted of reduced general activity and grazing but, especially, nocturnal activity. In parallel, the noise-rhythm relation became gradually reduced, as indicated by the HP, whereas the DFCs were reduced only during the transition period from high to low activity levels (Figure 5).

\section{Discussion}

The importance to domestic animals of research on biological rhythm has been expounded, for example, by Lefcourt (1990), whereas Tester and Figala (1990) underlined the importance of activity to wild animals. ETHOSYS II is highly suitable for research on biological rhythms, since in such research, knowledge of the time at which high or low behavior intensities occur is more important than precise knowledge of the current intensity level. It can be effectively used in scientific research, as well as in routine observation of high-value individuals or flocks under extensive rearing conditions.

Activity levels, measurable by ETHOSYS II, are recognized as valuable diagnostic indicators for medical problems and correlate with sleep/wake patterns, pain level, mood, energy expenditure, fatigue/alertness, and other quantifiable parameters. Therefore, ETHOSYS II can, for example, generally provide an objective record for tracking and documenting treatment effectiveness in sleep disorders, circadian rhythms disorders, disturbances brought on by shift work, or therapy of disturbed circadian rest-activity cycles in demented elderly.

The ETHOSYS method differs from other activityrecording instruments (such as Actiwatch, Actigraph, and others) in three respects: It allows continuous recording of up to four different behaviors, extremely long application without battery replacement, and wireless data transmission over long distances, which means that regular physical contact with the observed individual is not necessary. On the other hand, it is larger and heavier than one-channel instruments. 
Table 1

Degrees of Functional Coupling (DFCs) of Different Species Under Special Conditions or in Several Situations

\begin{tabular}{|c|c|c|c|c|c|c|}
\hline \multirow[b]{2}{*}{ Species } & \multirow{2}{*}{\multicolumn{2}{|c|}{ Conditions }} & \multicolumn{2}{|c|}{ DFC Activity } & \multicolumn{2}{|c|}{ DFC Feeding } \\
\hline & & & $M$ & $S D$ & $M$ & $S D$ \\
\hline \multirow[t]{6}{*}{ Red deer } & undisturbed & enclosure & 83.7 & 8.5 & 84.2 & 7.6 \\
\hline & & naturelike & 70.1 & 11.5 & 69.8 & 12.4 \\
\hline & disturbed & change of food regime $(n=2)$ & 100.0 & 0 & 0 & 0 \\
\hline & & unspecific chase $(n=17)$ & 6.4 & 5.4 & 4.4 & 2.8 \\
\hline & & antlers were cut off $(n=1)$ & 0 & & 51.7 & \\
\hline & & immobilization $(n=1)$ & 0 & & 16.6 & \\
\hline \multirow[t]{3}{*}{ Alpaca } & undisturbed & & 87.9 & 5.8 & 93.3 & 7.0 \\
\hline & disturbed & hurt $(n=1)$ & 27.6 & & 100.0 & \\
\hline & & parturition $(n=2)$ & 66.8 & 27.1 & 70.65 & 9.4 \\
\hline \multirow{5}{*}{$\begin{array}{l}\text { Przewalski } \\
\text { horse }\end{array}$} & undisturbed & zoo & 97.1 & 2.1 & 100.0 & 0 \\
\hline & & semireserve (first 2 years of adaptation) & 85.5 & 18.2 & 76.0 & 16.4 \\
\hline & & semireserve (after 2 years) & 90.3 & 14.1 & 91.4 & 14.6 \\
\hline & disturbed & introduction into semireserve (1st month) & 40.0 & 19.6 & 30.8 & 31.0 \\
\hline & & shooting noise in surrounding $(n=16)$ & 32.8 & 17.1 & 10.4 & 12.6 \\
\hline \multirow[t]{2}{*}{ Mouflon } & undisturbed & & 91.2 & 10.8 & 92.1 & 9.8 \\
\hline & disturbed & periparturition $(n=5)$ & 20.1 & 26.6 & 0 & 0 \\
\hline
\end{tabular}

A set of different procedures can be applied to the resulting time series for macroscopic and microscopic analytical methods.

Rhythms of physiological functions and related behaviors are essential components of the ecological relations between an organism and its environment. The ecological niche has been defined not only spatially, but also temporally (Remmert, 1969). There are many external conditions or internal processes by which the temporal organization of an organism may be adversely affected (Aschoff, 1969; Wever, 1985). For example, the heart rate of undisturbed tree shrews shows a clear diurnal pattern with ultradian components. Social stress altered this pattern not only in level, but also in frequency structure (Stöhr, 1986). Impairment of phase relations, changes in frequency structure, loss of rhythmicity, or reduction of amplitude are regarded as signs of adaptation, disease, or premortal state (Fontana Gasio et al., 2003; Skene \& Swaab, 2003). In such conditions, single functional systems react to stressors independently from the general synchronized time hierarchy of the organism. The lack of internal synchronization itself can be interpreted as a

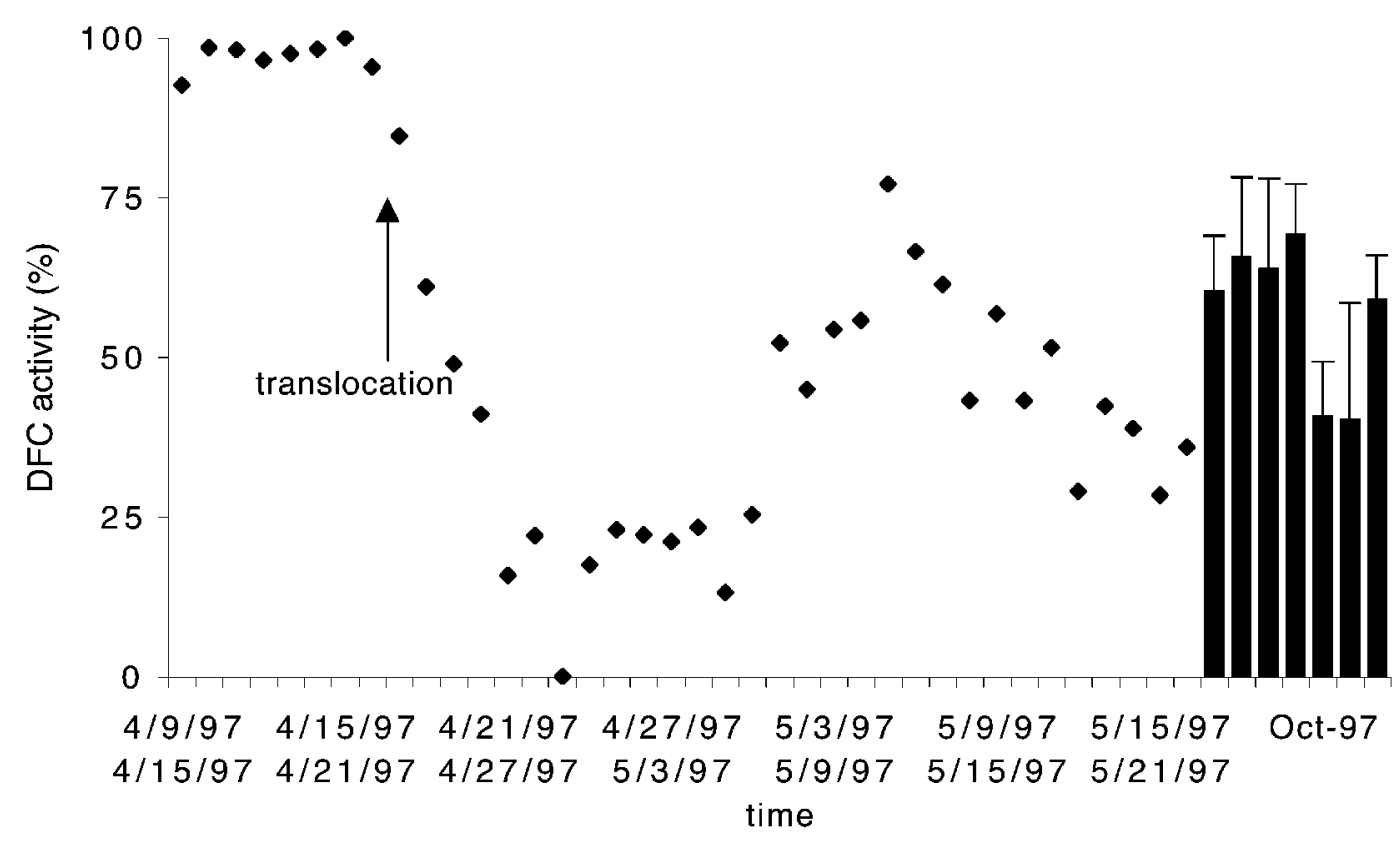

Figure 4. Degrees of functional coupling (DFCs) of activity of Przewalski horse Medi, calculated over overlapping periods of 7 days, with a delay of 1 day). On April 23, Medi was transferred from a zoo to the semireserve. 


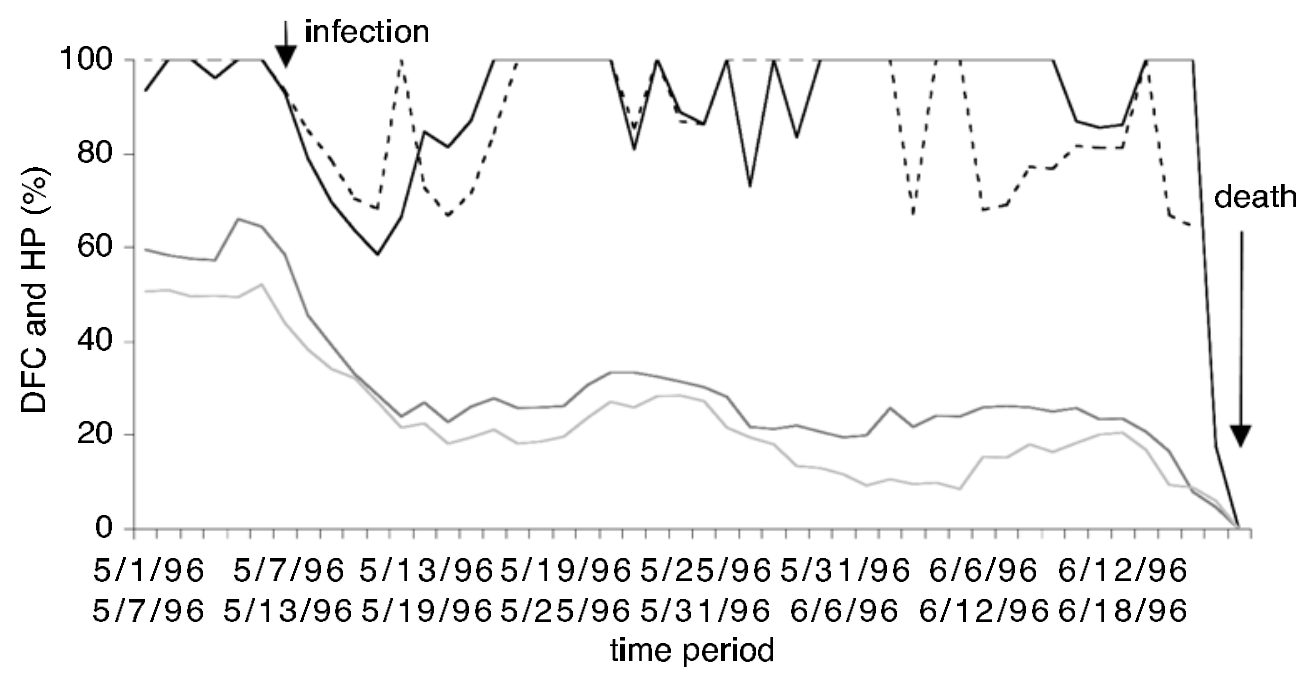

HP activity — DFC activity _ HP feeding - - - - - DFC feeding

Figure 5. Degrees of functional coupling (DFCs) and harmonic parts (HPs) of 1 sheep at pasture with parasitic infection. On June 24,1996 , the sheep died.

stressful situation (Bicakova-Rocher, Gorceix, Reinberg, Ashkenazi, \& Ticher, 1996; Daimon, Yamada, Tsuijimoto, \& Takahashi, 1992; Minors et al., 1996; Motohashi et al., 1987). Repetition of daily routines is an expression of hierarchic and harmonic temporal coordination between several physiological and behavioral systems and the zeitgeber and is characteristic for the healthy, unimpaired, and stress-free organism. Numerous observers have described more or less identical time patterns of behavior from day to day in stress-free conditions (Mayes \& Duncan, 1986; Michael, 1970).

Activity includes all behavioral patterns, from orientation to higher locomotor activity (e.g., for escape). Ultradian rhythms are major components of the time series observed. They occur in many physiological and behavioral functions of lower and higher animals, including man, and modulate circadian rhythms in a complex manner (Stupfel \& Pavely, 1990). The circadian and ultradian time structure of biological processes is not limited to pineal and pituitary hormones but includes, as well, other physiological aspects, such as glucose regulation and insulin secretion. The circadian rhythm of activity and sleep has bearings on this complex endocrine temporal organization and, in turn, is affected by the latter (Van Cauter, 1990). Ultradian rhythms of oxygen consumption or carbon dioxide emission correspond to ultradian rhythms of activity (Lloyd \& Stupfel, 1991). In domestic cattle, the time structure of body temperature and activity shows both ultradian and circadian components. Circadian, as well as ultradian, components were also visible in prolactin, but cortisol seemed to be determined solely by several ultradian components (Lefcourt, 1990).

A complete power spectrum displays the whole range of ultradian and circadian components (theoretically demonstrable by time series), depending only on sample interval and length of time series. The question arises as to how this information can be used to evaluate the current state of an organism. For example, reconstitution of rhythms of body weight, food and water consumption, and locomotor activity of rats after a phase shift of the zeitgeber has been followed up by means of spectral analysis under laboratory conditions (Minematsu, Watanabe, Hiruta, \& Amagaya, 1995).

DFCs (as an objective parameter of coordination of different organismic functions both with each other and with the external zeitgeber of circadian clocks) were developed to concentrate in one single value all the information of a spectral analysis on diurnal and ultradian rhythms (Sinz \& Scheibe, 1976). Following Aschoff's (1969) model of internal synchronization, they can be described as a presentation of both external and internal synchronization. This has been verified by investigations on various species under different conditions (e.g., Langbein \& Nichelmann, 1993; Scheibe \& Sinz, 1974).

Our observations show that ultradian rhythms are more affected than the circadian component by external disturbances and changing internal states and that DFCs are lowered in very different situations. They all have in common the tendency of forcing the organism to become adapted to new and more or less arousing situations, be it social isolation (Scheibe \& Sinz, 1974), social stress as described by Holst (1994), adaptation to thermal discomfort (Langbein \& Nichelmann, 1993), or structure of vegetation (Mitlöhner, 1996).

In our experiments, we found DFCs reduced by conditions that may be described as stress. Shooting is a type of noise of a highly particular nature. We observed, on several occasions after shots were fired, flight, restless- 
ness, and high vigilance in the group of Przewalski horses. This was in fair agreement with results reported by Herbold, Wagner, Suchentrunk, and Willing (1992), who found in roe deer and red deer that, out of all the acoustic disturbances tested, shots triggered the highest heart rate reaction.

The activity structure of one of the free-ranging individuals was affected for an extended period of time by immobilization and human activities inside the large enclosure. The generally low DFCs in this particular individual probably reflected its insufficient integration into the social system of the group.

Parturition is an event of greatest importance to a female organism. The process of parturition itself is not without risk to the mother and is accompanied by a decisive change to her daily routine. Parturition is triggered by a rise in the corticosteroid level and a resulting increase in placental production of estrogens. Physiology and behavior are substantively affected by the need for care of the young, lactation, and change in energy requirements. In mouflon, these endocrinological and behavioral changes began to take effect some days or hours before parturition and were characterized by lowered DFCs.

It is our conclusion that DFCs are high under normal, undisturbed conditions but may be reduced by either external stressors or endogenous functional changes. The criterion allows for quantitative comparison between different situations and can be used to describe the gravity of a stressor. It is, over a certain range, independent of the overall level of activity or the sensitivity of a sampling procedure. Hence, comparison is possible among DFCs obtained by means of different measuring devices.

Since this parameter can be automatically determined, it can be used as a routine for scanning procedures. Large data sets can be reduced to one single value, describing the rhythmic structure of the whole time series. DFCs can be used in statistical analysis. More or less subjective description of time patterns or even of power spectra can be replaced by objective measures.

Independent of different species-specific rhythmic patterns, DFC is one approach to quantitative assessment of this pattern. The assumption can be made that its application may provide meaningful results from time series in many species and various environments and may be useful for description of states in man and animals.

A function for future research could be assessment of treatment effectiveness, recording of long-time processes (such as age), and pinpointing the site(s) of agerelated dysfunction so that therapies can be specifically tailored to correct the abnormality, in addition to reinforcing any of the intact processes (Fontana Gasio et al., 2003). Additional comparative investigations, including those on reactions to different forms of stressors (e.g., heat, disease, pregnancy, birth, wounds, lack of resources, and others), are necessary to define species-specific standards of behavior-determining requirements of the environment. Further investigations might elucidate the extent to which the significant annual variations demonstrated in this study were determined by a usual yearly rhythm.

\section{REFERENCES}

Altmann, L. (1974). Observation study of behavior: Sampling methods. Behaviour, 49, 227-267.

ANDEl, J. (1984). Statistische Analyse von Zeitreihen. Berlin: Akademie-Verlag.

Aschoff, J. (1969). Desynchronization and resynchronization of human circadian rhythms. Aerospace Medicine, 40, 844-849.

Aschoff, J., Gerecke, U., \& Wever, R. (1967). Desynchronization of human circadian rhythms. Japanese Journal of Physiology, 17, 450457.

Bicakova-Rocher, A., Gorceix, A., Reinberg, A., Ashrenazi, I. I., \& Ticher, A. (1996). Temperature rhythm of patients with major affective disorders: Reduced circadian period length. Chronobiology International, 13, 47-57.

Daimon, K., Yamada, N., Tsuijimoto, T., \& Takahashi, S. (1992). Circadian rhythm abnormalities of deep body temperature in depressive disorders. Journal of Affective Disorders, 26, 191-198.

Fontana Gasio, P. F., Krauchi, K., Cajochen, C., van Someren, E., Amrhein, I., Pache, M., Savaskan, E., \& Wirz-Justice, A. (2003). Dawn-dusk simulation light therapy of disturbed circadian restactivity cycles in demented elderly. Experimental Gerontology, 38, 207-216.

Herbold, H., Wagner, S., Suchentrunk, F., \& Willing, R., (1992). Einfluß anthropogener Störreize auf die Herzfrequenz von Rotwild (Cervus elaphus) und Rehwild (Capreolus capreolus). Zeitschrift für Jagdwissenschaft, 38, 145-159.

HoLST, D. vON (1994). Auswirkungen sozialer Kontakte bei Säugetieren. Biologie in Unserer Zeit, 24, 164-173.

LANGBein, J., \& NichelmanN, M. (1993). Comparative study of rectal temperature and of the 24-hour activity in cattle (Holstein, Friesian and Siboney de Cuba) on tropical pasture. Zoologisches Jahrbuch: Physiologie, 97, 173-185.

LEFCOURT, A. M. (1990). Circadian and ultradian rhythms in ruminants: Relevance to farming and science. Progress in Clinical \& Biological Research, 341B, 735-753.

Lloyd, D., \& STUPFEl, M. (1991). The occurrence and functions of ultradian rhythms. Biological Review, 66, 275-299.

Mayes, E., \& Duncan, P. (1986). Temporal patterns of feeding behaviour in free-ranging horses. Behaviour, 96, 105-129.

Mercer, D. M. A. (1965). The limitations of detection of periodicities in random noise. In J. Aschoff (Ed.), Circadian clocks (pp. 23-30). Amsterdam: North-Holland.

Michael, E. (1970). Activity patterns of white-tailed deer in South Texas. Texas Journal of Science, 21, 417-428.

Minematsu, S., Watanabe, M., Hiruta, M., \& Amagaya, S. (1995). Re-entrainment of body weight, food and water consumption and spontaneous motor activity rhythms in rats after a light-dark cycle reversal. Journal of Experimental Animal Technology, 30, 87-95.

Minors, D., Akerstedt, T., At kinson, G., Dahlitz, M., Folkard, S., \& LeVI, F. (1996). The difference between activity when in bed and out of bed: I. Healthy subjects and selected patients. Chronobiology International, 13, 27-34.

MitlöHNER, F. (1996). Einflüsse der Baumbestandsdichte auf verschiedene produktionswirksame Verhaltensweisen bei Zeburindern im Grand Chaco Boreal, Paraguay. Unpublished thesis, University of Leipzig.

Motohashi, Y., Reinberg, A., Bourdeleau, P., Benoit, O., Levi, F., Nouguier, J., \& Touitou, Y. (1987). Internal desynchronization of circadian rhythms documented longitudinally in subjects with good and poor tolerance to shift work. Chronobiologia, 14, 213.

Remmert, H. (1969). Tageszeitliche Verzahnung der Aktivität verschiedener Organismen. Oecologia, 3, 214-226.

Scheibe, K.-M., Berger, A., Langbein, J., Streich, W. J., \& EichHORN, K. (1999). Comparative analysis of ultradian and circadian behavioural rhythms for diagnosis of biorhythmic state of animals. Biological Rhythm Research, 30, 1-18. 
Scheibe, K.-M., \& Schleusner, T. (1993). Vorrichtung zum Erfassen motorischer Parameter von Wirbeltieren einschließlich des Menschen. Deutsches Patent Nr. 4227 483, München 25.11. 1993.

ScheIBE, K.-M., \& Sinz, R. (1974). Korrelations- und spektralanalytische Untersuchungen über die Aktivitätsrhythmen zur Optimierung der Intensivhaltungsbedingungen in der Lämmermast. Monatshefte für Veterinärmedizin, 29, 410-415.

Sinz, R. \& ScheIBE, K.-M. (1976). Systemanalyse der multioszillatorischen Funktionsordnung im zirkadianen und ultradianen Frequenzbereich und ihr Indikationswert für Belastungswirkungen, dargestellt am Beispiel verschiedener Licht-Dunkel-Verhältnisse bei der Intensivhaltung von Schafen. Acta Biologica et Medica Germaniae, 35, 465-414.

SKENE, D. J., \& SWAAB, D. F. (2003). Melatonin rhythmicity: Effect of age and Alzheimer's disease. Experimental Gerontology, 38, 199 206.

STöHR, W. (1986). Heart rate of tree shrews and its persistent modification by social contact. In T. H. Schmidt, T. M. Dembroski, \& G. Blümchen (Eds.), Biological and psychological factors in cardiovascular disease (pp. 491-499). Heidelberg: Springer-Verlag.
Stupfel, M., \& Pavely, A. (1990). Ultradian, circahoral and circadian structures in endothermic vertebrates and humans. Comparative Biochemistry \& Physiology, 96A, 1-11.

SzYMANSKI, J. S. (1920). Aktivität und Ruhe bei Tieren und Menschen. Zeitschrift für allgemeine Physiologie, 18, 105-162.

Tester, J. R., \& Figala, J. (1990). Effects of biological and environmental factors on activity rhythms of wild animals. In D. K. Hayes, J. E. Pauly, \& R. J. Reiter (Eds.), Chronobiology: Its role in clinical medicine, general biology, and agriculture (pp.909-919). New York: Wiley.

VAn CAuter, E. (1990). Diurnal and ultradian rhythms in human endocrine function: A minireview. Hormone Research, 34, 45-53.

WeVER, R. A. (1985). Internal interactions within the human circadian system: The masking effect. Experientia, 41, 332-342.

(Manuscript received September 17, 2002; revision accepted for publication May 14, 2003.) 